\title{
Rol de las relaciones públicas en los destinos turísticos que sufren atentados terroristas: análisis de la comunicación de crisis realizada en Londres, Mánchester y París tras los atentados de 2017
}

\section{Assumpció Huertas ${ }^{1}$ \\ Andrea Oliveira ${ }^{2}$ \\ Nora Balagué López ${ }^{3}$}

Recibido: 09/04/2019

Aprobado por pares: 05/10/2019
Enviado a pares: 22/04/2019

Aceptado: 07/10/2019

DOI: 10.5294/pacla.2021.24.1.6

Para citar este artículo / to reference this article / para citar este artigo Huertas, A., Oliveira, A. y Balagué López, N. (2021). Rol de las relaciones públicas en los destinos turísticos que sufren atentados terroristas: análisis de la comunicación de crisis realizada en Londres, Mánchester y París tras los atentados de 2017. Palabra Clave, 24(1), e2416. https://doi.org/10.5294/pacla.2021.24.1.6

\section{Resumen}

Los atentados terroristas suponen un impacto negativo en la imagen de los destinos, que afecta a su demanda turística y genera una crisis en el sector turístico. Por ello, el objetivo de este artículo es verificar cómo las organizaciones de marketing de los destinos (OMD) de Londres, Mánchester y París gestionaron esta crisis durante y después de los atentados en 2017 desde una perspectiva de las relaciones públicas. Para ello, se realizó un análisis de contenido de los tuits publicados en las cuentas oficiales de los destinos

\footnotetext{
https://orcid.org/0000-0001-6684-4220. Universitat Rovira i Virgili, España. sunsi.huertas@urv.cat

$2 \triangle$ https://orcid.org/0000-0002-1370-6139. Profesora Serra Húnter, Universitat de Girona, España. andrea.oliveira@udg.edu

3 https://orcid.org/0000-0001-5210-6577. Investigadora independiente, España.
} 
a lo largo de 30 días tras los atentados terroristas. A partir de la literatura existente sobre comunicación de crisis, se elaboró una plantilla de análisis que analizó el timming, el formato y el contenido de los tuits, así como las reacciones que generaron en los públicos. Los resultados muestran que las tres OMD centraron sus esfuerzos comunicativos en la difusión de contenidos de promoción turística para gestionar la crisis, pero, a pesar de que los públicos desean estar informados cuando acontece un atentado para entender lo ocurrido y sentirse seguros, las OMD comunicaron poco o nada sobre el tema. Además, los tuits que informaron sobre la gestión del atentado realizada y la protección a los stakeholders fueron los que obtuvieron mayores reacciones entre los públicos. Las principales contribuciones del estudio son la plantilla de análisis creada para el análisis de la comunicación de crisis de los destinos y haber demostrado que los públicos valoran la información recibida sobre el atentado y la gestión de protección realizada por parte de las OMD.

\section{Palabras clave (Fuente: tesauro de la Unesco)}

Relaciones públicas; organizaciones de marketing de los destinos; redes sociales; gestión de crisis; terrorismo; Europa; comunicación; comunicación de crisis. 


\section{The Role of Public Relations in Tourist Attractions under Terrorist Attacks: Analysis of the Crisis Communication in London, Manchester, and Paris after the 2017 Attacks}

\section{Abstract}

Terrorist attacks have a negative impact on destination image, affecting their tourism demand and generating a crisis in the tourism sector. The objective of this article is to investigate how the Destination Marketing Organizations (DMOs) of London, Manchester and Paris managed the crisis during and after the terrorist attacks of 2017 from a Public Relations perspective. A content analysis method of the tweets published in the official account profiles of said destinations was carried out during the 30 days that followed the terrorist attacks. Based on the existing literature on crisis communication, an analysis template was developed that analysed the timing, format and content of the tweets, as well as the reactions they generated in the public. The results indicate that the $3 \mathrm{DMOs}$ focused their communication efforts on the dissemination of messages to promote tourism in the region in order to manage the crisis, but despite the fact that the public want to be informed when an attack occurs to understand what happened and feel safe, DMOs communicated little or nothing about what happened in the attack. In addition, the tweets that reported on the management of the attack carried out and the protection of stakeholders were the ones that obtained the greatest reactions among the public. The main contributions of the study are the analysis template created for the analysis of destinations' crisis communication and the fact that public value the information received about the attack and the protection management carried out by the DMOs.

\section{Keywords (Source: Unesco Thesaurus)}

Public relations; destination marketing organizations; social media; crisis management; terrorism; Europe; communication; crisis communication. 


\section{0 papel das relações públicas nos destinos turísticos que sofrem atentados terroristas: análise da comunicação de crise realizada em Londres, Manchester e Paris depois dos atentados de 2017}

\section{Resumo}

Os atentados terroristas supõem um impacto negativo na imagem dos destinos, que afeta a sua demanda turística e gera uma crise no setor turístico. Por isso, o objetivo deste artigo é verificar como as organizações de marketing de destinos (OMD) de Londres, Manchester e Paris gerenciaram essa crise durante e após os atentados em 2017 a partir de uma perspectiva das relações públicas. Para isso, realizou-se uma análise de conteúdo dos tuítes publicados nas contas oficiais dos destinos ao longo de 30 dias depois dos atentados terroristas. A partir da literatura existente sobre comunicação de crise, elaborou-se um formulário de análise que analisou o timming, o formato e o conteúdo dos tuítes, bem como as reações que geraram nos públicos. Os resultados mostram que as três OMD centraram seus esforços comunicativos na difusão de conteúdos de promoção turística para gerenciar a crise, mas, apesar de os públicos desejarem estar informados quando acontece um atentado para entender o ocorrido e se sentirem seguros, as OMD comunicaram pouco ou nada sobre o tema. Além disso, os tuítes que informaram sobre o gerenciamento do atentado realizado e a proteção aos stakeholders foram os que obtiveram maiores reações entre os públicos. As principais contribuições do estudo são o formulário de análise criado para a análise da comunicação de crise dos destinos e ter demonstrado que os públicos valorizam a informação recebida sobre o atentado e o gerenciamento de proteção realizada por parte das OMD.

\section{Palavras-chave (Fonte: tesauro da Unesco)}

Relações públicas; organizações de marketing de destino; redes sociais; gestão de crises; terrorismo; Europa; comunicação; comunicação de crise. 


\section{Introducción}

Los atentados terroristas comportan un gran impacto negativo en la imagen de los territorios y los destinos (Liu y Pratt, 2017; Pizam y Mansfeld, 2006). Ello afecta directamente a la demanda turística (Araña y León, 2008) y genera crisis para el sector turístico (Crijns et al., 2017; Krakover, 2005; Pizam, 1999; Ritchie, 2004), ya que ante un mínimo riesgo percibido la demanda turística disminuye (Ritcher y Waugh, 1986; Ryan, 1993). En estas situaciones de caos y crisis, los turistas (Cho y Boster, 2005), como el resto de individuos, se sienten desprotegidos (Martínez et al., 2017) y necesitan información (Kievik et al., 2012), para sentirse seguros y entender qué ha ocurrido (Martínez et al., 2017). Por ello, se requiere que las organizaciones de marketing de los destinos (OMD) realicen una adecuada comunicación de crisis.

Los atentados de Londres, Mánchester y París de 2017 afectaron directamente el sector turístico porque se realizaron en lugares de gran afluencia turística, siendo turistas algunas de las víctimas. Además, estas ciudades son destinos turísticos destacados mundialmente que reciben millones de visitantes al año. Por ello, la afectación de los atentados fue en especial relevante para el sector turístico y para la imagen de estos destinos.

Actualmente, la imagen de los destinos es un aspecto clave para la atracción de turistas, ya que influye decisivamente en sus mentes para la elección de estos (Baloglu y McCleary, 1999; Castillo et al., 2019; Chen y Tsai, 2007; Goodrich, 1978; Hunt, 1975; Lee y Gretzel, 2012; Milman y Pizam, 1995; Nadeau et al., 2008; Milman y Pizam, 1995). Así pues, dada la necesidad de que los destinos tengan buena imagen, tras un atentado terrorista son necesarias las relaciones públicas y la gestión comunicativa de crisis para que la imagen de los destinos que han sufrido atentados no se vea tan afectada. Pero todavía falta mucho para que las teorías y la gestión de la comunicación de crisis se desarrollen tanto en el ámbito profesional de la gestión de los destinos como en el ámbito académico de su investigación (Oliveira y Huertas, 2019). Por ello, se pretende destacar la importancia y la necesidad del rol de las relaciones públicas y de una correcta comunicación de crisis en los destinos turísticos cuando se producen atentados terroristas. 
Los medios sociales son destacados canales de relaciones públicas para la gestión de la comunicación de las crisis (Freberg et al., 2013; Wan et al., 2015). Diversos estudios previos han demostrado la importancia de Twitter en este ámbito (Fowler, 2017; Wang y Zhuang, 2017; Xu y Wu, 2015). Por tanto, el objetivo es analizar la comunicación de crisis que realizaron las OMD de Londres, Mánchester y París en sus plataformas oficiales de Twitter después de los atentados de 2017. Para ello, se creó una metodología de análisis a partir de la literatura en relaciones públicas sobre comunicación de crisis en los destinos tras atentados terroristas. Esta metodología ya ha sido testada en estudios previos (Oliveria y Huertas, 2018, 2019) y ha quedado totalmente demostrada su utilidad para evaluar si la comunicación realizada por las OMD fue adecuada para la gestión de la crisis y la recuperación de la imagen de los destinos.

\section{Marco teórico}

\section{Estudios sobre terrorismo y comunicación de crisis en los destinos turísticos}

De la literatura en relaciones públicas cabe destacar que las teorías sobre comunicación de crisis, como la teoría de restauración de la imagen de Benoit (1997) o la teoría situacional de comunicación de crisis de Coombs $(1998,2007)$, se centran en las crisis organizacionales y no son de fácil aplicación para los destinos turísticos que sufren atentados terroristas (Avraham, 2015; Ketter, 2016), porque existen grandes diferencias con las crisis que se producen en las organizaciones. Además, los destinos no son empresas, sino entidades más amplias y complejas que incluyen diversos públicos. Con todo, la literatura en relaciones públicas (Coombs, 1998; Dougherty, 1992) sí aporta un extenso conocimiento sobre comunicación de crisis que puede ser de utilidad para los destinos turísticos que han sufrido atentados.

Coombs (1998) y Dougherty (1992) destacaron la importancia de una comunicación rápida después de la crisis y de la predisposición a revelar información verdadera y completa a los medios. La comunicación debe ser rápida y consistente, informar de lo que ha sucedido, explicar lo que se ha hecho para solucionar el problema y proteger a los stakeholders y, poste- 
riormente, comunicar para recuperar la imagen. Coombs (1998) demostró que el discurso de compasión con las víctimas aumentaba el apoyo de los stakeholders y mejoraba las percepciones de reputación e imagen.

Los estudios académicos de relaciones públicas centrados en comunicación de crisis (Liu et al., 2011; Ulmer y Sellnow 2002; Ulmer et al.,2007) o en atentados terroristas (Crijns et al., 2017; Guo, 2017) también comportan contribuciones que pueden ser de aplicación para el ámbito turístico de los destinos. Ulmer y Sellnow (2002) y Ulmer et al. (2007) destacaron el discurso de renovación para la comunicación después de las crisis. A pesar de que también se centran en las crisis organizacionales, sus recomendaciones son de total utilidad para la recuperación de la imagen de los destinos turísticos que han sufrido atentados. Consideran que los discursos optimistas y de renovación, junto con un compromiso en la correcta gestión de la crisis, ayudan a reconstruir la confianza de los stakeholders y la imagen que estos se crean, y así ayudar a la recuperación de la imagen de los destinos.

Los estudios recientes centrados en terrorismo también aportan conocimiento de utilidad para los destinos turísticos. Crijns et al. (2017) analizaron la gestión comunicativa gubernamental tras los atentados terroristas de Bélgica y cómo la percibieron los ciudadanos. Afirman que los gobiernos y las instituciones deben proteger su reputación cuando acontecen atentados con una correcta comunicación de crisis basada en la experiencia y la honestidad. Así, aumenta la confianza de los públicos hacia estas instituciones. Por otro lado, Guo (2017) analizó las emociones de los públicos tras el atentado de Boston de 2013 y destacó la importancia del discurso de renovación y el fomento de las emociones positivas.

Por otro lado, los estudios académicos desde la disciplina del turismo sobre terrorismo se han centrado ampliamente en demostrar el gran impacto de los atentados en la disminución de la demanda turística (Araña y León, 2008; Krakover, 2005; Liu y Pratt, 2017; Pizam, 1999). Pero menos estudios han analizado el impacto del terrorismo en la creación de la imagen del destino (Chew y Jahari, 2014) y muy pocos su gestión tras atentados terroristas. Además, en la literatura predominan los estudios desde la 
perspectiva marketiniana (Avraham, 2015; Avraham y Ketter, 2008; Beirman, 2002; Ketter, 2016; Ritchie, 2004; Sönmez et al., 1999) en detrimento de la perspectiva comunicativa (Avery et al., 2010). Algunos analizan las acciones para la recuperación de la imagen de los destinos (Avraham, 2015; Ketter, 2016) tras crisis por inestabilidad política o desastres naturales, pero no tras atentados terroristas. Otros estudian la comunicación realizada por los gobiernos tras atentados terroristas, pero no desde el sector turístico (Crijns et al., 2017; Guo, 2017).

Autores como Sönmez et al. (1999) o Ritchie (2004) reconocen que el terrorismo supone crisis para los destinos, que daña su imagen en aspectos como la seguridad y la atracción que generan, y consideran que solo una correcta gestión de las crisis puede evitar el daño a la imagen del destino. En la misma línea, otros autores afirman que tras una crisis hay oportunidades para recuperar la imagen (Ulmer et al., 2007) y que se deben aplicar teorías y conceptos de otras disciplinas comunicativas para la gestión de las crisis en el ámbito del turismo (Avraham, 2015; Avraham y Ketter, 2008; Beirman, 2002; Ketter, 2016; Ritchie, 2004; Sönmez et al., 1999). En general, estos autores, aunque reconocen la importancia de las relaciones públicas y las estrategias de comunicación de crisis, no centran la investigación desde la perspectiva comunicativa. Granville et al. (2016), en cambio, adoptan una perspectiva de relaciones públicas para analizar la gestión de las crisis cuando se producen desastres en los destinos, pero también se centran más en las diversas fases de la gestión comunicativa que en la propia comunicación realizada.

Así pues, es necesario que tanto profesionales como académicos entiendan que los atentados terroristas suponen crisis de imagen para los destinos y que las OMD deben realizar una correcta comunicación de crisis cuando estos se producen, estableciendo relaciones con los públicos (Granville et al., 2016). Por tanto, se necesita el desarrollo de modelos teóricos, metodologías de análisis e investigación desde el ámbito de las relaciones públicas (Huertas, 2008) que sirvan tanto para analizar como para guiar la correcta comunicación de las crisis en los destinos turísticos cuando se producen atentados terroristas. 


\section{Twitter y los medios sociales: herramientas clave en la gestión de la comunicación de crisis}

Internet, la revolución tecnológica y los medios sociales han supuesto grandes cambios para la gestión de las relaciones de las organizaciones con sus públicos, en general, y para la comunicación de crisis, en particular. De hecho, el surgimiento de los medios sociales ha comportado grandes ventajas para la comunicación de las crisis respecto de los medios anteriores (Liu et al., 2011). No se puede afirmar que exista una guía establecida y consensuada para gestionar las actividades de las organizaciones en los medios sociales, pero no cabe duda de que estos son herramientas estratégicas con un gran potencial para transformar la manera en que se relacionan las organizaciones con sus públicos (Chung et al., 2017).

Los medios sociales ofrecen muchas ventajas para la comunicación de crisis y también para la posterior recuperación de la imagen de los destinos (Liu y Fraustino, 2014). Por ello, se utilizan ampliamente en este tipo de comunicaciones (Wang y Zhuang, 2017), por su rapidez de información (Wan et al., 2015) y su potencial interactivo (Jaeger et al., 2007; Seltzer y Mitrook, 2007). Además, permiten a los usuarios tanto consultar como compartir informaciones (Stephens y Malone, 2009) sobre lo ocurrido o sobre los atentados (Bruns y Hanusch, 2017). Como consecuencia, los medios sociales tienen una gran influencia en las opiniones y percepciones de los públicos (Lerbinger, 2011). Como muestran Liu et al. (2011), durante las crisis los públicos utilizan más los medios sociales y dan mayor credibilidad a sus informaciones que a las del resto de medios (Sweetser y Metzgar, 2007).

Diversos estudios académicos se han centrado en la comunicación de crisis a través de los medios sociales. Mientras Freberg et al. (2013) analizaron la distribución informativa de los medios sociales durante las crisis, Shuai et al. (2012) se centraron en el impacto de esa información. Freberg et al. (2013), incluso, exploraron cómo se comparte la información en los medios sociales, en atención al riesgo de compartir informaciones en abierto en estas plataformas (Van der Meer y Verhoeven, 2013). Liu et al. (2011) analizaron cómo son usados los medios sociales por los usuarios durante las 
crisis, cómo se informan y qué comparten, mientras que Bruns y Hanusch (2017), las imágenes que los usuarios o públicos compartían tras un atentado terrorista. De los recursos disponibles en las redes sociales, los vídeos son los que generan mayor nivel de engagement (Pletikosa y Michahelles, 2013). No obstante, las imágenes y los textos son los más utilizados por las organizaciones para compartir contenidos (Capriotti et al., 2019), y el uso de estos mensajes en las plataformas digitales es dos veces superior al de los recursos audiovisuales (Capriotti et al., 2016). En una situación de crisis como los atentados, sin embrago, una de las recomendaciones de la policía es que no se publiquen fotografías ni vídeos en las redes por respeto a las víctimas y a sus familiares (Llanos, 2016), además para no perjudicar el operativo policial (Atresmedia, 2017). Pero, a pesar de todos estos estudios, todavía existe poca investigación evaluativa para saber si la comunicación de crisis ha sido la adecuada y si su distribución y contenidos han sido eficaces durante y después de las crisis (Wang y Zhuang, 2017) para recuperar la imagen de los destinos.

El creciente número de estudios sobre el uso de Twitter en el campo de las relaciones públicas, en general (Capriotti y Ruesja, 2018), y de comunicación de crisis, en particular (Fowler, 2017; Oliveira y Huertas, 2018, 2019), evidencia las posibilidades de esta herramienta dialógica en la gestión comunicativa entre las organizaciones y sus públicos, y entre las OMD y los turistas. Twitter ha sido el medio social más utilizado para la comunicación de crisis (Wang y Zhuang, 2017). Su uso es en especial efectivo en situaciones dinámicas, inciertas y extremas (Zhang et al., 2011) debido a su naturaleza instantánea y accesible (Choi, 2012; Fowler, 2017). La rapidez de Twitter puede ahorrar mucho tiempo e, incluso, salvar vidas (Coombs, 2015), dado que proporciona actualizaciones rápidas de información. Las principales potencialidades de Twitter para la comunicación de crisis son su simplicidad de uso, la gran frecuencia de publicaciones que permite y los links a otros sites (Greer y Ferguson, 2011), así como la interacción en tiempo real (Capriotti y Ruesja, 2018; Knight y Carpenter, 2012), que es, en especial, efectivo para fomentar la participación de los stakeholders involucrados activamente en las crisis (Briones et al., 2011). 
Fowler (2017) investigó el uso de Twitter por la policía tras un atentado analizando el potencial y las limitaciones de este medio social para la comunicación de crisis. Wang y Zhuang (2017) también examinaron la información difundida por Twitter tras una crisis provocada por un huracán. Xu y Wu (2015) estudiaron el uso de Twitter durante las crisis en las organizaciones norteamericanas y demostraron que su uso disminuye la evaluación negativa de los públicos. Igualmente, Schultz et al. (2011) comprobaron que el medio importa más que el mensaje y que Twitter genera menos reacciones negativas hacia las crisis que otros medios. Oliveira y Huertas $(2018,2019)$ investigaron cómo Barcelona Turismo y Cambrils Turismo utilizaron Twitter para gestionar la comunicación de crisis durante del atentado de agosto de 2017 en Cambrils y Barcelona, y crearon una metodología de análisis para la comunicación de crisis en Twitter tras atentados terroristas en los destinos. Esta metodología quedó testada en ese estudio, pero es necesario hacer más investigación en esta línea para conocer cómo los destinos turísticos internacionales utilizan Twitter para su comunicación de crisis.

\section{Metodología}

Este estudio se ha centrado en analizar los contenidos publicados por las OMD París Turismo, Londres Turismo y Mánchester Turismo a través de sus cuentas oficiales de Twitter tras los atentados terroristas de 2017, para identificar sus prácticas comunicativas online con sus públicos turísticos y conocer si realmente realizaron una correcta comunicación de crisis para recuperar su imagen como destinos.

\section{Casos de estudio}

Se seleccionaron los atentados de París, Londres y Mánchester de 2017, porque, debido a que tuvieron lugar en ciudades que son destacados destinos turísticos y en zonas de máxima afluencia de turistas, su afectación al ámbito turístico ha sido destacada. En el Reino Unido, se perpetraron tres atentados terroristas en 2017 en un breve periodo, dos en Londres y uno en Mánchester (Martínez et al., 2017).El 22 de marzo de 2017, en el puente de Westminster, un turismo a $120 \mathrm{~km} / \mathrm{h}$ atropelló a la gente que allí se encontraba. Seis personas murieron y 49 resultaron heridas. El 22 de mayo, tras 
un concierto multitudinario en el Mánchester Arena, explotó una bomba, murieron 23 personas y resultaron heridas 250 . Por otro lado, el 3 de junio, en el puente de Londres y el mercado de Borough, una furgoneta atropelló a viandantes. Algunas víctimas también fueron agredidas con arma blanca. En este último atentado, murieron 11 personas y 48 resultaron heridas.

En cuanto al atentado de París, el 20 de abril de 2017, un hombre armado disparó y mató a un policía e hirió de gravedad a otros dos en los Campos Elíseos, en el centro de París, justo cuando faltaban pocos días para las elecciones presidenciales.

\section{Preguntas de investigación}

Para alcanzar los objetivos del estudio, se establecieron cuatro preguntas de investigación:

RQ1: ¿Con qué timming París Turismo, Londres Turismo y Mánchester Turismo comunicaron los atentados a través de su plataforma de Twitter?

RQ2: ¿Qué formato de recursos de información París Turismo, Londres Turismo y Mánchester Turismo utilizaron para comunicar los atentados a través de Twitter?

RQ3: ¿Cuáles son los principales contenidos de los tuits de las tres OMD tras los atentados?

RQ4: ¿Qué tipo de reacción se generó entre los públicos a partir de los mensajes publicados por las tres OMD tras los atentados?

\section{Plantilla de análisis}

Para responder a las preguntas de investigación planteadas, se realizó un análisis de contenido de los tuits a partir de la aplicación de la plantilla desarrollada por Oliveira y Huertas (2018). Se analizaron los tuits publicados por las tres OMD (París, Londres y Mánchester) a lo largo de un mes tras los atentados terroristas. Cabe destacar que se examinaron solo los tuits propios de cada destino, excluyendo los retuits, porque se quería sa- 
ber cómo las tres $\mathrm{OMD}$ contribuyeron en la creación directa de contenido durante la gestión de la comunicación de crisis. Según Oliveira y Huertas (2018), los destinos deben aprovechar las potencialidades de Twitter y convertirse en actores partícipes de la gestión de crisis, y no ser simplemente reproductores de contenido. En la misma línea, Granville et al. (2016) destacan la importancia de que las organizaciones sean fuente primaria de información y tomen la iniciativa comunicativa en momentos de crisis. Por ello, la plantilla creada es una herramienta clave para analizar la implicación que las OMD analizadas tuvieron en la comunicación del atentado a los turistas y su comunicación posterior para reposicionar la imagen del destino (Crijns et al., 2017).

La plantilla de análisis se diseñó a partir de la literatura sobre relaciones públicas y comunicación de crisis (Coombs, 1998, 2007; Dougherty, 1992) y de la literatura sobre crisis y medios sociales (Fowler, 2017; Freberg et al., 2013; Guidry et al., 2017; Wang y Zhuang, 2017). Además, se consideraron las particularidades propias de los atentados en destinos turísticos y las informaciones que un destino tiene que comunicar posteriormente para recuperar su imagen (Ulmery Sellnow, 2002; Ulmer et al., 2007; Coombs, 2007). Finalmente, a la plantilla de análisis desarrollada por Oliveira y Huertas (2018) se añadieron, a partir de otros estudios existentes (Capriotti et al., 2019), elementos sobre los recursos de información que las organizaciones suelen utilizar en las redes sociales para comunicarse con sus públicos.

Para contestar la RQ1, la plantilla de análisis solicitaba la fecha del tuit. Esto es una información necesaria para evaluar la comunicación realizada, ya que, según Coombs (1998) y Dougherty (1992), en comunicación de crisis la rapidez de la reacción comunicativa es un factor clave para su éxito.

Para responder la RQ2, se contempló en la plantilla de análisis los formatos de recursos de información que las OMD utilizaron para difundir los mensajes, inspirados en las categorías aplicadas en el estudio desarrollado por Capriotti et al. (2019). Así, se seleccionaron tres tipos de formatos: recursos gráficos (texto, imagen, emoticono), audiovisuales (imagen animada, audio-vídeo) e interactivos (link, hashtag, etiqueta a usuarios). 
Para responder la RQ3, que se centraba en el análisis de contenido, siguiendo a Coombs (2007) y Ulmer et al. (2007), la plantilla se estructuró en dos categorías principales: de comunicación sobre lo ocurrido y gestión del atentado, y de comunicación para recuperar la imagen. Cada una de estas categorías se subdividió en dos subcategorías y diversos ítems de análisis.

La primera categoría pretendía analizar si se efectuó una correcta comunicación del atentado y de su gestión. Esta categoría englobó las subcategorías: comunicación de lo ocurrido y comunicación de la gestión y protección a los stakeholders. La subcategoría comunicación sobre lo ocurrido comprendía la información sobre el atentado y la descripción de los hechos, e incluía ítems como qué pasó, cuándo, dónde y por qué. En cambio, la subcategoría de gestión y protección a los stakeholders comprendía la información sobre las soluciones que se realizaron para gestionar el atentado, y comprendía ítems como rechazo del atentado, asistencia a turistas, frenar rumores, etc.

La segunda categoría de comunicación para recuperar la imagen abarcaba otras dos subcategorías: la comunicación sobre seguridad al turista y la comunicación y promoción turística. La subcategoría de comunicación de seguridad pretendía analizar si las OMD habían comunicado acciones para que los turistas percibieran los destinos como lugares seguros y comprendía ítems como creación de medidas de seguridad en espacios turísticos (pilonas, alarmas, cámaras, etc.), creación de apps, publicación de normativas, consejos, etc. En cambio, la subcategoría de la comunicación y promoción turística pretendía analizar las acciones de comunicación turística posteriores realizadas con un discurso positivo y de renovación por el destino para recuperar su imagen (Ulmer y Sellnow, 2002; Ulmer et al., 2007), y englobaba ítems como información sobre exposiciones, conciertos y eventos en el destino, remodelaciones y aperturas de nuevas atracciones turísticas, creación de nuevo material de promoción turística, etc.

Por último, para contestar la RQ4, la plantilla pretendía analizar las reacciones de los usuarios a los tuits analizados a través de la medición de los me gusta conseguidos, que medía el apoyo recibido por el tuit, y el número de veces que este fue compartido, que medía su difusión. Además, las 
reacciones muestran el éxito de la comunicación, traducido en una mejor imagen y superior demanda turística (Uşaklı et al., 2017).

Para el análisis se llevó a cabo la recuperación de todos los tuits publicados, a través de la búsqueda avanzada en Twitter, de las cuentas @ParisJeTaime, @visit_mcr y @visit_london, filtrando los resultados desde el día del atentado hasta 30 días después: París Turismo, del 20 de abril de 2017 al 20 de mayo de 2017; Mánchester Turismo, del 22 de mayo de 2017 al 22 de junio de 2017, y Londres Turismo, del 3 de junio de 2017 al 3 de julio de 2017. Se obtuvieron 253 tuits, de los cuales 93 eran de París Turismo, 60 de Mánchester Turismo y 100 de Londres Turismo.

El análisis de contenido de los tuits a través de esta plantilla de análisis se realizó de forma manual durante noviembre y diciembre de 2018.

\section{Resultados}

Respecto de la cantidad de tuits publicados, Londres Turismo, Mánchester Turismo y París Turismo publicaron 253 en un periodo de 30 días. De este total, que configura la muestra analizada, un $40 \%$ son de Londres Turismo, un 36,76 \% de París Turismo y un 23,72 \% de Mánchester Turismo. Las tres OMD en conjunto publicaron una media de 8,4 tuits diarios, de los cuales París Turismo publicó una media de 3,1 tuits diarios, Mánchester Turismo 2 tuits diarios y Londres Turismo 3,3 tuits diarios.

El análisis del timing (RQ1) muestra que las tres OMD publicaron precisamente una menor cantidad de tuits durante las dos primeras semanas después de sus respectivos atentados que después (Londres Turismo el 41 \%, París Turismo difundió el 43 \% y Mánchester Turismo el 36,7 \%). Además, cabe destacar que Londres Turismo y Mánchester Turismo no publicaron ningún mensaje durante 12 y 6 días, respectivamente, mientras que París Turismo solo un día de los 30 no publicó ningún tuit.

Si bien es cierto que París Turismo publicó hasta cinco tuits el día del atentado y seis el día posterior (el mayor volumen diario de tuits que este destino publicó fue de seis diarios), también lo es que la cantidad se redu- 
ce significativamente en los días posteriores al atentado, con una variación de uno o dos diarios. En la misma lógica, Mánchester Turismo publicó hasta cuatro tuits el día del atentado (cuatro fue la mayor cantidad publicados en un único día). Pero este destino disminuyó su actividad en Twitter en los días posteriores al atentado, incluso, tuvo actividad nula en los días sexto y séptimo tras el atentado. En sentido contrario, Londres Turismo solo publicó cuatro tuits el día del atentado, pero difundió hasta 12 en el séptimo día posterior al atentado, 11 en el décimo y 15 en el vigesimoséptimo. En atención a las fechas de los atentados, se puede afirmar que Mánchester Turismo y Londres Turismo publicaron, con bastante rapidez, un tuit que hacía referencia al suceso; a diferencia de París Turismo, que no difundió ningún contenido sobre los hechos. Cabe destacar que los atentados de Mánchester y Londres fueron por la noche y los destinos hicieron un primer tuit sobre el suceso al día siguiente (figura 1).

\section{Figura 1. Timing de la publicación de los tuits tras los atentados}

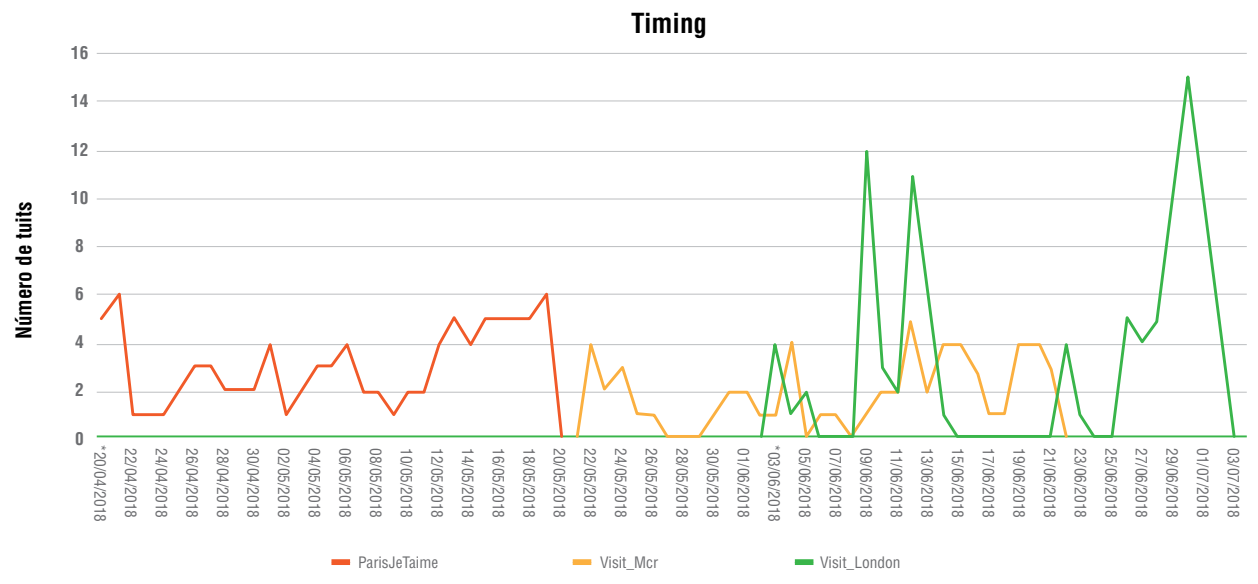

Fuente: elaboración propia.

Respecto de los formatos de los recursos de información (RQ2) (tabla 1), se puede observar que, en general, París Turismo, Mánchester Turismo y Londres Turismo recurrieron más a los recursos gráficos para difundir los contenidos en Twitter. La totalidad de los tuits poseen texto y muchos de ellos (más del $80 \%$ ) imágenes fijas para acompañarlo. Por otra parte, 
las $\mathrm{OMD}$ se valen, con bastante frecuencia, de recursos interactivos, tales como hashtags $(76,7 \%)$ y links (68\%). En cambio, se muestra que las tres OMD apostaron en menor medida por los recursos audiovisuales (solo el $8,7 \%)$ para difundir contenido. Tan solo algo más del $5 \%$ de los tuits contienen vídeos y solo el 3,2 \% imágenes animadas.

Tabla 1. Formato de los recursos de información

\begin{tabular}{|c|c|c|c|c|c|c|c|c|}
\hline & \multicolumn{2}{|c|}{ General } & \multicolumn{2}{c|}{ París } & \multicolumn{2}{c|}{ Mánchester } & \multicolumn{2}{c|}{ Londres } \\
\cline { 2 - 10 } & Frecuencia & $\%$ & Frecuencia & $\%$ & Frecuencia & $\%$ & Frecuencia & $\%$ \\
\hline Recursos interactivos & 194 & 76,7 & 80 & 86 & 39 & 65 & 75 & 75 \\
\hline Recursos gráficos & 253 & 100 & 93 & 100 & 60 & 100 & 100 & 100 \\
\hline Recursos audiovisuales & 22 & 8,7 & 7 & 7,5 & 2 & 3,4 & 13 & 13 \\
\hline Total & $\mathbf{2 5 3}$ & & 93 & & 60 & & 100 & \\
\hline
\end{tabular}

Fuente: elaboración propia.

Si se comparan las tres OMD, se observa que todas utilizaron principalmente los recursos gráficos (texto e imagen). Sin embargo, cabe destacar una diferencia en el uso de recursos interactivos: París Turismo y Londres Turismo utilizaron más hashtags ( 86 y $75 \%$ ) que links (69,9 y $59 \%$ ) para difundir contenido, mientras que Mánchester Turismo recurrió más a los links (65\%) que a los hashtags (59\%). Por último, se observa que París Turismo y Londres Turismo publicaron más vídeos $(5,4$ y $8 \%)$ que imágenes animadas $(2,2$ y $5 \%)$ en su contenido, mientras que Mánchester Turismo los publicaron en igual proporción $(1,7 \%)$.

Si analizamos el contenido de los tuits (RQ3) centrándonos en las cuatro categorías de análisis de la plantilla creada (tabla 2), se observa que prácticamente ninguna de las tres OMD comunica lo ocurrido. Mánchester Turismo tan solo tiene un tuit sobre ello y Londres dos. Pero París ni uno solo. Así pues, parece que las organizaciones turísticas no quieren comunicar sobre los atentados, a pesar de ser un tema clave para los públicos turísticos que se encuentran en esos destinos y ello es necesario para una correcta comunicación de crisis (Granville et al., 2016). Por otro lado, Mánchester Turismo comunica protección a los stakeholders en un 27,3 \% de sus tuits y Londres Turismo solo en un 10,2 \% de ellos. El porcentaje de 
Londres Turismo es bajo, pero el de París Turismo es inexistente. A pesar de la importancia de comunicar la gestión que se ha realizado para proteger a los stakeholders (Coombs, 1998), este contenido es prácticamente inexistente, a excepción de los tuits de Mánchester Turismo.

Por otro lado, para recuperar la imagen de los destinos una vez ocurridos los atentados, es fundamental comunicar las medidas de seguridad que se han tomado para evitar que vuelva a ocurrir (Coombs, 2007) y realizar una comunicación turística positiva (Ulmer y Sellnow, 2002; Ulmer et al., 2007). Por ello, resulta sorprendente que ninguno de los tuits de las tres OMD tratara sobre las medidas de seguridad adoptadas. En cambio, la mayoría de tuits de las tres OMD sí comunicaron positivamente para seguir promocionando el turismo. Ello es fundamental para recuperar la imagen y lo hicieron correctamente. De hecho, París Turismo solo comunica esta última temática en todos sus tuits y Londres Turismo en un $87,9 \%$ de ellos.

Si se examinan los temas tratados en cada subcategoría (tabla 2), se observa que París Turismo, Mánchester Turismo y Londres Turismo, en la tipología "turismo posatentado", publicaron casi un $50 \%$ de los tuits con información sobre "atractivos y espacios turísticos", mostrando fotografías de paisajes, monumentos, lugares con encanto, etc. En menor medida, las OMD difundieron un poco más de un $25 \%$ de los mensajes sobre "eventos en el destino", donde recordaron celebraciones propias de cada país, tradiciones, o simplemente informaron sobre exposiciones, obras de teatro, museos, cine o conciertos que se realizaron en el periodo analizado. Las tres OMD publicaron menos de un $10 \%$ de los tuits sobre temas como "experiencias turísticas" (9,58 \%), "material de promoción turística” (5,42\%) que informaba sobre las distintas promociones especiales ofrecidas en su momento, "nuevas atracciones" $(2,08 \%)$ que presentaba inauguraciones, eventos o puntos turísticos nuevos, "nuevos productos y servicios" y "asistencia a ferias", ambos con solo un mensaje $(0,42 \%)$.

De manera más específica, si comparamos las tres OMD, se observa que todas publicaron su mayor volumen de tuits sobre "atractivos y espacios turísticos" (54,84, 42,31 y 47,37 \%). En este sentido, París Turismo compartió predominantemente contenido digital con fotografías de loca- 
lizaciones atractivas y concurridas en la ciudad, Mánchester Turismo optó por fotografías muy artísticas y con encanto tanto de puntos emblemáticos como de lugares más comerciales y Londres Turismo publicó preponderantemente fotografías de paisajes típicos y emblemáticos de la ciudad. En cambio, cada cual divulgó información sobre los "eventos en el destino" de forma distinta. Mánchester Turismo centró su atención en este tema en casi la mitad de sus tuits, mientras que París Turismo lo hizo en casi una tercera parte de ellos (31,18\%), y Londres Turismo, en menos de un $15 \%$ de sus publicaciones. Por otra parte, Londres Turismo apostó por difundir las "experiencias turísticas” en casi una quinta parte de sus tuits (17,89\%), mientras París Turismo y Mánchester Turismo lo hicieron en menos ocasiones (solo publicaron 4,30 y 3,85 \% de estos mensajes). De forma similar, Londres Turismo publicó casi un $12 \%$ de su contenido sobre "material turístico", mientras las otras dos OMD lo hicieron escasamente (menos del $2 \%$ ).

Tabla 2. Tipología y contenidos de los tuits publicados

\begin{tabular}{|c|c|c|c|c|c|c|c|c|}
\hline & \multicolumn{2}{|c|}{ General } & \multicolumn{2}{|c|}{ París } & \multicolumn{2}{|c|}{ Mánchester } & \multicolumn{2}{|c|}{ Londres } \\
\hline & Frecuencia & $\%$ & Frecuencia & $\%$ & Frecuencia & $\%$ & Frecuencia & $\%$ \\
\hline $\begin{array}{l}\text { Atentado/comunicar lo } \\
\text { ocurrido }\end{array}$ & 3 & & 0 & & 1 & & 2 & \\
\hline Descripción hechos & 2 & 66,67 & 0 & 0,00 & 1 & 100 & 1 & 50 \\
\hline $\begin{array}{l}\text { Identificación } \\
\text { responsable }\end{array}$ & 0 & 0,00 & 0 & 0,00 & 0 & 0,00 & 0 & 0,00 \\
\hline Número de heridos & 0 & 0,00 & 0 & 0,00 & 0 & 0,00 & 0 & 0,00 \\
\hline Número de muertos & 1 & 33,33 & 0 & 0,00 & 0 & 0,00 & 1 & 50,00 \\
\hline Protección stakeholders & 31 & & 0 & & 20 & & 11 & \\
\hline Solidaridad/rechazo & 19 & 61,29 & 0 & 0,00 & 14 & 70,00 & 5 & 45,45 \\
\hline Actualizada & 2 & 6,45 & 0 & 0,00 & 1 & 5,00 & 1 & 9,09 \\
\hline Útil & 3 & 9,68 & 0 & 0,00 & 1 & 5,00 & 2 & 18,18 \\
\hline Asistencia & 0 & 0,00 & 0 & 0,00 & 0 & 0,00 & 0 & 0,00 \\
\hline Cogestión de la crisis & 0 & 0,00 & 0 & 0,00 & 0 & 0,00 & 0 & 0,00 \\
\hline Agradecimientos & 3 & 9,68 & 0 & 0,00 & 1 & 5,00 & 2 & 18,18 \\
\hline Otra & 0 & 0,00 & 0 & 0,00 & 0 & 0,00 & 0 & 0,00 \\
\hline Soluciones & 4 & 12,90 & 0 & 0,00 & 3 & 15 & 1 & 9,09 \\
\hline Frenar rumores & 0 & 0,00 & 0 & 0,00 & 0 & 0,00 & 0 & 0 \\
\hline Turismo posatentado & 240 & & 93 & & 52 & & 95 & \\
\hline $\begin{array}{l}\text { Atractivos y espacios } \\
\text { turísticos }\end{array}$ & 118 & 49,17 & 51 & 54,84 & 22 & 42,31 & 45 & 47,37 \\
\hline
\end{tabular}




\begin{tabular}{|c|c|c|c|c|c|c|c|c|}
\hline & \multicolumn{2}{|c|}{ General } & \multicolumn{2}{|c|}{ París } & \multicolumn{2}{|c|}{ Mánchester } & \multicolumn{2}{|c|}{ Londres } \\
\hline & Frecuencia & $\%$ & Frecuencia & $\%$ & Frecuencia & $\%$ & Frecuencia & $\%$ \\
\hline Eventos en el destino & 67 & 27,92 & 29 & 31,18 & 24 & 46,15 & 14 & 14,74 \\
\hline Experiencias turistas & 23 & 9,58 & 4 & 4,30 & 2 & 3,85 & 17 & 17,89 \\
\hline Nuevas atracciones & 5 & 2,08 & 2 & 2,15 & 2 & 3,85 & 1 & 1,05 \\
\hline Otra & 11 & 4,58 & 4 & 4,30 & 1 & 1,92 & 6 & 6,32 \\
\hline $\begin{array}{l}\text { Apps para difusión } \\
\text { turística }\end{array}$ & 1 & 0,42 & 1 & 1,08 & 0 & 0,00 & 0 & 0,00 \\
\hline $\begin{array}{l}\text { Nuevos productos y } \\
\text { servicios turísticos }\end{array}$ & 1 & 0,42 & 0 & 0,00 & 0 & 0,00 & 1 & 1,05 \\
\hline Souvenirs & 0 & 0,00 & 0 & 0,00 & 0 & 0,00 & 0 & 0,00 \\
\hline Asistencia a ferias & 1 & 0,42 & 1 & 1,08 & 0 & 0,00 & 0 & 0,00 \\
\hline Workshops turísticos & 0 & 0,00 & 0 & 0,00 & 0 & 0,00 & 0 & 0,00 \\
\hline $\begin{array}{l}\text { Material de promoción } \\
\text { turística }\end{array}$ & 13 & 5,42 & 1 & 1,08 & 1 & 1,92 & 11 & 11,58 \\
\hline $\begin{array}{l}\text { Bloggers, youtubers o } \\
\text { instagramers de turismo }\end{array}$ & 0 & 0,00 & 0 & 0,00 & 0 & 0,00 & 0 & 0,00 \\
\hline Seguridad posatentado & 0 & & 0 & & 0 & & 0 & \\
\hline Medidas de seguridad & 0 & 0,00 & 0 & 0,00 & 0 & 0,00 & 0 & 0,00 \\
\hline $\begin{array}{l}\text { Medios digitales de } \\
\text { seguridad }\end{array}$ & 0 & 0,00 & 0 & 0,00 & 0 & 0,00 & 0 & 0,00 \\
\hline Normativas de actuación & 0 & 0,00 & 0 & 0,00 & 0 & 0,00 & 0 & 0,00 \\
\hline $\begin{array}{l}\text { Presencia de cuerpos } \\
\text { seguridad }\end{array}$ & 0 & 0,00 & 0 & 0,00 & 0 & 0,00 & 0 & 0,00 \\
\hline
\end{tabular}

Fuente: elaboración propia.

En segundo lugar, Mánchester Turismo y Londres Turismo publicaron tuits sobre protección a los stakeholders, pero, sorprendentemente, París Turismo no publicó ningún tuit con este contenido. Así pues, Mánchester Turismo publicó hasta 20 tuits con este tema. Se puede afirmar que el $85 \%$ de los tuits en esta categoría se centraron en el rechazo al atentado o en la solidaridad con las víctimas. Ejemplo de ello es la promoción del concierto de Ariadna Grande y otros cantantes internacionalmente famosos para recaudar fondos para las familias de las víctimas y los afectados. Mánchester Turismo publicó también un $5 \%$ de sus tuits con tres temas distintos: "agradecimientos" dirigidos a los equipos de emergencia y a los ciudadanos valientes, "información actualizada" sobre el concierto solidario e "información útil” centrado en dónde encontrar más información sobre la gestión del atentado. De forma similar, Londres Turismo publicó poco más 
de la mitad de sus tuits manifestando "rechazo" al atentado o mostrando "solidaridad" con las víctimas o familiares, y divulgando las diferentes manifestaciones que se organizaron en contra del atentado. En menor medida, Londres Turismo publicó mensajes de "agradecimiento" hacia los cuerpos de seguridad de la ciudad, "información útil" sobre la gestión del atentado, por ejemplo, el cierre del supermercado Borough, e "información actualizada" sobre la gestión del atentado, con un único tuit, para informar dónde se podía ir a donar sangre para ayudar a las víctimas.

Resulta sorprendente el bajo número de tuits que las OMD publicaron para comunicar lo ocurrido. Mánchester Turismo publicó un único tuit sobre el tema con información sobre el atentado, y Londres Turismo, tan solo dos tuits comunicando, además de lo ocurrido, el número de fallecidos en la tragedia y las palabras del alcalde de la comunidad. Resulta sorprendente que, dada la importancia de informar sobre lo ocurrido, París Turismo no publicara ningún tuit sobre el tema.

Si observamos la reacción de los usuarios a los tuits analizados (RQ4), los resultados obtenidos indican que todos los tuits publicados en conjunto por las tres OMD obtuvieron 22958 me gusta, mientras que se realizaron 8651 comparticiones, casi una tercera parte de los me gusta.

Londres Turismo obtuvo 11583 me gusta, lo que supone una media de 115,83 me gusta por tuit, y poco más de 386 por día. En comparación, París Turismo recibió 6577 me gusta, con una media de 70,72 por publicación, y 219 me gusta por día. Finalmente, los tuits de Mánchester Turismo consiguieron 4798 me gusta, lo que supone una media de 79,97 por tuit y casi 160 por día.

Referente a las comparticiones, los tuits publicados por Londres $\mathrm{Tu}$ rismo generaron 3830 comparticiones, con una media de 38,3 por publicación y de 127,67 comparticiones por día. Por otro lado, los de París Turismo obtuvieron 2593 comparticiones totales, con una media de 27,88 por publicación y poco más de 86 por día. Por último, se identifica que los tuits de Mánchester Turismo fueron compartidos 222 veces, lo que supuso de media 37,13 comparticiones por mensaje, y 74,27 por día. 


\section{Conclusiones}

El estudio muestra que, a pesar de que la cantidad y frecuencia de tuits de las tres OMD durante los atentados y los días posteriores fue similar entre ellos y correcta, ya que publicaron una media de más de tres tuits cada entidad, muy pocos en el caso de Londres Turismo y ninguno en el caso de París Turismo trataron del atentado. A pesar de que los públicos turísticos desean estar informados para entender lo ocurrido y sentirse seguros (Coombs, 2007), París Turismo no comunicó lo ocurrido en ninguno de sus tuits, aunque publicó cinco tuits el mismo día del atentado y seis al día siguiente. Por otra parte, también resulta sorprendente que el número de tuits de las tres OMD disminuyeran en las dos semanas posteriores a los atentados. Pero si consideramos que los atentados estuvieron poco o nada presentes en el contenido de los tuits de alguna OMD, entonces se entiende que disminuyera su número.

Respecto de la comunicación sobre qué se hizo para solucionar el problema y proteger a los stakeholders, el estudio muestra resultados muy distintos para las tres OMD analizadas. Mientras Mánchester Turismo publicó casi la mitad de sus tuits sobre este tema, Londres Turismo una cantidad muy inferior y París Turismo ninguno. A pesar de que este contenido es fundamental para una correcta gestión de la crisis, según estudios previos en relaciones públicas (Coombs, 1998), y para generar una buena imagen entre los stakeholders, París Turismo no lo tuvo presente en ninguno de sus tuits.

Los resultados del estudio han demostrado que París Turismo no se implicó para nada en la comunicación del atentado, a pesar de la importancia de la implicación de las administraciones públicas y las instituciones en una correcta comunicación de crisis cuando acontecen atentados (Crijns et al., 2017). Ello resulta sorprendente si consideramos que un atentado afecta la sensación de seguridad de los turistas y que las OMD son el canal directo de comunicación con ellos (Granville et al., 2016). El hecho de no comunicar nada de lo ocurrido, como en el caso de París Turismo, y seguir comunicando los atractivos turísticos en un momento como ese, pudo comportar una imagen negativa para la institución y para el destino (Crijns et al., 2017). 
Por otro lado, desde el ámbito de las relaciones públicas, para recuperar la imagen de los destinos tras atentados terroristas, es fundamental comunicar las medidas de seguridad tomadas para evitar que vuelvan a ocurrir (Coombs, 2007) y realizar una comunicación turística positiva (Coombs, 2007; Ulmer y Sellnow, 2002; Ulmer et al., 2007). Curiosamente, ninguno de los tuits de las tres OMD trataron sobre las medidas de seguridad adoptadas, lo cual supone una valoración negativa de este aspecto de su comunicación de crisis. En cambio, la mayoría de tuits de las tres OMD sí comunicaron positivamente el destino y sus atractivos turísticos. Ello es fundamental para recuperar la imagen (Ulmer y Sellnow, 2002; Ulmer et al., 2007), y todas lo hicieron ampliamente. De hecho, París Turismo solo comunicó este aspecto en todos sus tuits y Londres Turismo en un $87,9 \%$ de ellos.

El estudio también demuestra que las tres OMD utilizan, mayoritariamente, texto con imágenes, como recursos de información para gestionar la crisis en Twitter. Estos resultados, a primera vista, parecerían contradecir las recomendaciones de que durante los atentados terroristas no es conveniente mostrar vídeos ni imágenes de las víctimas o del atentado (Capriotti et al., 2019; Llanos, 2016). Sin embargo, cabe destacar que los tuits sobre el atentado son pocos o inexistentes y que las OMD, preponderantemente, difundieron contenido de promoción turística en el periodo analizado y que los recursos de información empleados para este tipo de contenido son adecuados. Asimismo, cabe señalar que las tres OMD no utilizan imágenes o vídeos en ninguno de los tres tuits con información directa sobre el ataque terrorista (lo ocurrido), sino que se hacen servir solo textos para este contenido.

Las reacciones de los usuarios confirman el agrado y la implicación de los públicos con los tuits publicados (Seltzer y Mitrook, 2007), y el estudio muestra que Londres Turismo es el que obtuvo más likes y comparticiones. Además, a pesar de que París Turismo obtuvo más reacciones que Mánchester Turismo, los tuits de esta última lograron un porcentaje superior de media de likes por tuit que los de París Turismo. En la investigación, no se puede comparar de manera óptima qué tipo de contenido posee más fuerza para generar mayores reacciones en los usuarios, debido a los esca- 
sos tuits publicados sobre los atentados y a la ausencia de tuit sobre seguridad posatentado. No obstante, las reacciones van en convergencia con la literatura, ya que, como se ha demostrado, el hecho de comunicar sobre la gestión del atentado y la protección a los stakeholders genera mayor implicación e imagen entre los públicos (Coombs, 2007).

Así pues, los destinos han sabido aprovechar las potencialidades de Twitter para la comunicación de crisis posterior a los atentados terroristas que sufrieron, pero su gestión de crisis ha sido desigual entre las tres OMD. A pesar de que han comunicado mejor la promoción turística para recuperar su imagen que los atentados en sí mismos, todavía queda mucho para que las $\mathrm{OMD}$ de los destinos se impliquen en una correcta comunicación de crisis y realicen una eficaz gestión de las relaciones públicas en todos sus aspectos (Granville et al., 2016).

Finalmente, el estudio también ha demostrado que la plantilla de análisis utilizada creada por Oliveira y Huertas (2018) es una herramienta clave para analizar la implicación que las OMD analizadas tuvieron en la comunicación del atentado con los turistas y también su correcta comunicación de crisis y su comunicación posterior para reposicionar la imagen del destino (Crijns et al., 2017).

Una de las limitaciones del estudio es no haber podido utilizar herramientas de análisis automatizadas de los tuits en la investigación, dado que la plantilla de análisis creada era mucho más amplia y compleja y no permitía la aplicación del análisis automatizado. Con todo, los avances en la creación de herramientas de análisis semántico son significativos y para investigaciones futuras se tratará de adaptarlas al análisis de la comunicación de crisis.

\section{Referencias}

Araña, J. E. y León, C. J. (2008). The impact of terrorism on tourism demand. Annals of Tourism Research, 35(2), 299-315. https://doi. org/10.1016/j.annals.2007.08.003 
Atresmedia (2017, 17 de agosto). Las fuerzas de seguridad piden no publicar las imágenes del operativo desplegado por el atentado en las Ramblas. Atresmedia Noticias. https://www.antena3.com/noticias/sociedad/fuerzas-seguridad-piden-publicar-imagenes-atentado-ramblas_201708175995c7eb0cf2e2ea35529064.html

Avery, E. J., Lariscy, R. W., Kim, S. y Hocke, T. (2010). A quantitative review of crisis communication research in public relations from 1991 to 2009. Public Relations Review, 36(2), 190-192. https:// doi.org/10.1016/j.pubrev.2010.01.001

Avraham, E. (2015). Destination image repair during crisis: Attracting tourism during the Arab Spring uprisings. Tourism Management, 47, 224-232. https://doi.org/10.1016/j.tourman.2014.10.003

Avraham, E. y Ketter, E. (2008). Will we be safe there? Analysing strategies for altering unsafe place images. Place Branding and Public Diplomacy, 4(3), 196-204. https://doi.org/10.1057/pb.2008.10

Baloglu, S. y McCleary, K. W. (1999). A model of destination image formation. Annals of Tourism Research, 26(4), 868-897. https://doi. org/10.1016/S0160-7383(99)00030-4

Beirman, D. (2002). Marketing of tourism destinations during a prolonged crisis: Israel and the Middle East. Journal of Vacation Marketing, 8(2), 167-176. https://doi.org/10.1177/135676670200800206

Benoit, W. L. (1997). Image repair discourse and crisis communication. Public Relations Review, 23(2), 177-186. https://doi.org/10.1016/ S0363-8111(97)90023-0

Briones, R. L., Kuch, B., Liu, B. F. y Jin, Y. (2011). Keeping up with the digital age: How the American Red Cross uses social media to build relationships. Public Relations Review, 37(1), 37-43. https://doi. org/10.1016/j.pubrev.2010.12.006 
Bruns, A. y Hanusch, F. (2017). Conflict imagery in a connective environment: Audiovisual content on Twitter following the 2015/2016 terror attacks in Paris and Brussels. Media, Culture \& Society, 39(8), 1122-1141. https://doi.org/10.1177/0163443717725574

Capriotti, P., Carretón, C. y Castillo, A. (2016). Testing the level of interactivity of institutional websites: From museums 1.0 to museums 2.0. International Journal of Information Management, 36(1), $97-$ 104. http://doi.org/10.1016/j.ijinfomgt.2015.10.003

Capriotti, P. y Ruejas, L. (2018). How CEOs use Twitter: A comparative analysis of Global and Latin American companies. International Journal of Information Management, 39(1), 242-248. https://doi. org/10.1016/j.ijinfomgt.2018.01.003

Capriotti, P., Zeler, I. y Oliveira, A. (2019). Comunicación dialógica 2.0 en Facebook: Análisis de la interacción en las organizaciones de América Latina. Revista Latina de Comunicación Social, 74, 10941113. DOI: $10.4185 /$ RLCS-2019-1373

Castillo, A., Carriilo-Durán, M. V. y Luengo-Chávez, G. (2019). La comunicación de la marca de las cadenas hoteleras a través de sus sedes web: propuesta de un modelo para su gestión. Palabra Clave, 22(2), e22211. https://doi.org/10.5294/pacla.2019.22.2.11

Chen, C. F. y Tsai, D. (2007). How destination image and evaluative factors affect behavioral intentions? Tourism Management, 28(4), 11151122. https://doi.org/10.1016/j.tourman.2006.07.007

Chew, E. Y. T. y Jahari, S. A. (2014). Destination image as a mediator between perceived risks and revisit intention: A case of post-disaster Japan. Tourism Management, 40, 382-393. https://doi. org/10.1016/j.tourman.2013.07.008

Cho, H. y Boster, F. J. (2005). Development and validation of value-, outcome-, and impression-relevant involvement sca- 
les. Communication Research, 32(2), 235-264. https://doi. org/10.1177/0093650204273764

Choi, J. (2012). Crisis communication through Twitter. En S. Duhé (ed.), New media and public relations (2. ${ }^{a}$ ed., pp. 311-319). Peter Lang PublishingInc.

Chung, A. Q. H., Andreev, P., Benyoucef, M., Duane, A. y O'Reilly, P. (2017). Managing an organisation's social media presence: An empirical stages of growth model. International Journal of Information Management, 37(1), 1405-1417. https://doi.org/10.1016/j.ijinfomgt.2016.10.003

Coombs, W. T. (1998). An analytic framework for crisis situations: Better responses from a better understanding of the situation. Journal of Public Relations Research, 10(3), 177-191. https://doi. org/10.1207/s1532754xjprr1003_02

Coombs, W. T. (2007). Attribution theory as a guide for post-crisis communication research. Public Relations Review, 33(2), 135-139. https:// doi.org/10.1016/j.pubrev.2006.11.016

Coombs, W. T. (2015). The value of communication during a crisis: Insights from strategic communication research. Business Horizons, 58(2), 141-148. https://doi.org/10.1016/j.bushor.2014.10.003

Crijns, H., Cauberghe, V.y Hudders, L. (2017). Terrorism threat in Belgium: The resilience of Belgian citizens and the protection of governmental reputation by means of communication. Public Relations Review, 43(1), 219-234. https://doi.org/10.1016/j.pubrev.2016.10.006

Dougherty, D. (1992). Crisis communications: What every executive needs to know. Walker.

Fowler, B. M. (2017). Stealing thunder and filling the silence: Twitter as a primary channel of police crisis communication. Public Re- 
lations Review, 43(4), 718-728. https://doi.org/10.1016/j.pubrev.2017.04.007

Freberg, K., Palenchar, M. J. y Veil, S. R. (2013). Managing and sharing H1N1 crisis information using social media bookmarking services. Public Relations Review, 39(3), 178-184. https://doi. org/10.1016/j.pubrev.2013.02.007

Goodrich, J. N. (1978). The relationship between preferences for and perceptions of vacation destinations: Application of a choice model. Journal of Travel Research, 17(2), 8-13. https://doi. org/10.1177/004728757801700202

Granville, F., Mehta, A. y Pike, S. (2016). Destinations, disasters and public relations: Stakeholder engagement in multi-phase disaster management. Journal of Hospitality and Tourism Management, 28, 73-79. https://doi.org/10.1016/j.jhtm.2016.02.001

Greer, C. F. y Ferguson, D. A. (2011). Using Twitter for promotion and branding: A content analysis of local television Twitter sites. Journal of Broadcasting $y$ Electronic Media, 55(2), 198-214. https://doi. org/10.1080/08838151.2011.570824

Guidry,J.,Jin, Y., Orr, C. A., Messner, M. y Meganck, S. (2017). Ebola on Instagram and Twitter: How health organizations address the health crisis in their social media engagement. Public Relations Review, 34(4), 477-486. https://doi.org/10.1016/j.pubrev.2017.04.009

Guo, S. J. (2017). The 2013 Boston marathon bombing: Publics' emotions, coping, and organizational engagement. Public Relations Review, 43(4), 755-767. https://doi.org/10.1016/j.pubrev.2017.07.003

Huertas, A. (2008). Public relations and tourism: Fighting for the role of public relations in tourism. Public Relations Review, 43(1), 406408. https://doi.org/10.1016/j.pubrev.2008.07.001 
Hunt,J.D. (1975).Image as a factorin tourism development.Journal of Travel Research, 13(3), 1-7.https://doi.org/10.1177/004728757501300301

Jaeger, P. T., Shneiderman, B., Fleischmann, K. R., Preece, J., Qu, Y. y Wu, P. F. (2007). Community response grids: E-government, social networks, and effective emergency management. Telecommunications Policy, 31(10), 592-604. https://doi.org/10.1016/j.telpol.2007.07.008

Ketter, E. (2016). Destination image restoration on Facebook: The case study of Nepal's Gurkha Earthquake. Journal of Hospitality and Tourism Management, 28, 66-72. https://doi.org/10.1016/j. jhtm.2016.02.003

Kievik, M., ter Huurne, E. F. y Gutteling, J. M. (2012). The action suited to the word? Use of the framework of risk information seeking to understand risk-related behaviors. Journal of risk research, 15(2), 131147. https://doi.org/10.1080/13669877.2011.601318

Knight, M. y Carpenter, S. (2012). Optimal matching model of social support: An examination of how national product and service companies use Twitter to respond to consumers. Southwestern Mass Communication Journal, 27(2), 21-35. https://www.academia. edu/7176975/Optimal_matching_model_of_social_support_ An_examination_of_how_national_product_and_service_companies_use_Twitter_to_respond_to_the_public

Krakover, S. (2005). Estimating the effect of atrocious events on the flow of tourists to Israel. En G. Ashworth y R. Hartmann (eds.), Horror and human tragedy revisited: The management of sites of atrocities for tourism (pp. 183-194). Cognizant Communication Corporation.

Lee, W. y Gretzel, U. (2012). Designing persuasive destination websites: A mental imagery processing perspective. Tourism Management, 33(5), 1270-1280. https://doi.org/10.1016/j.tourman.2011.10.012 
Lerbinger, O. (2011). The crisis manager: Facing disasters, conflicts, and failures. Routledge.

Liu, B. F. y Fraustino, J. D. (2014). Beyond image repair: Suggestions for crisis communication theory development. Public Relations Review, 40(3), 543-546. https://doi.org/10.1016/j.pubrev.2014.04.004

Liu, B. F., Austin, L. y Jin, Y. (2011). How publics respond to crisis communication strategies: The interplay of information form and source. $\mathrm{Pu}$ blic Relations Review, 37(4), 345-353. https://doi.org/10.1016/j. pubrev.2011.08.004

Liu, A. y Pratt, S. (2017). Tourism's vulnerability and resilience to terrorism. Tourism Management, 60, 404-417.https://doi.org/10.1016/j.tourman.2017.01.001

Llanos Martínez, H. (2016). ¿Quién regula las imágenes de víctimas de atentados en la era de las redes sociales? El País. https://verne.elpais. com/verne/2016/07/15/articulo/1468569905_007905.html

Martínez Solana, M. Y., Nogueira Frazão, A. G. y Valarezo, K. P. (2017). Gestión de la comunicación de crisis en los atentados de 2017 en reino unido: propuesta de un protocolo 2.0 para la comunicación de crisis. Revista Latina de Comunicación Social, 72, 1566-1591. https://doi.org/10.4185/RLCS-2017-1235

Milman, A. y Pizam, A. (1995). The role of awareness and familiarity with a destination: The central Florida case. Journal of Travel Research, 33(3), 21-27. https://doi.org/10.1177/004728759503300304

Nadeau, J., Heslop, L., O’Reilly, N. y Luk, P. (2008). Destination in a country image context. Annals of tourism Research, 35(1), 84-106. https://doi.org/10.1016/j.annals.2007.06.012 
Oliveira, A. y Huertas, A. (2018). La comunicación de crisis de Barcelona tras el atentado terrorista. Revista Internacional de relaciones públicas, 8(15), 5-22. http://dx.doi.org/10.5783/RIRP-15-2018-02-05-22

Oliveira, A. y Huertas, A. (2019). How do destinations use Twitter to recover their images after a terrorist attack? Journal of Destination Marketing y Management, 12, 46-54. https://doi.org/10.1016/j. jdmm.2019.03.002

Pletikosa Cvijikj, I. y Michahelles, F. (2013). Online engagement factors on Facebook brand pages. Social Network Analysis and Mining, 3(4), 843-861. http://doi.org/10.1007/s13278-013-0098-8

Pizam, A. (1999). A comprehensive approach to classifying acts of crime and violence at tourism destinations. Journal of Travel Research, 38(1), 5-12. https://doi.org/10.1177/004728759903800103

Pizam, A. y Mansfeld, Y. (2006). Toward a theory of tourism security. En Y. Mansfeld y A. Pizam (eds.), Tourism, security and safety: From theory to practice (pp. 1-27). Routledge.

Richter, L. K. y Waugh Jr, W. L. (1986). Terrorism and tourism as logical companions. Tourism Management, 7(4), 230-238. https://doi. org/10.1016/0261-5177(86)90033-6

Ritchie, B. W. (2004). Chaos, crises and disasters: A strategic approach to crisis management in the tourism industry. Tourism Management, 25(6), 669-683. https://doi.org/10.1016/j.tourman.2003.09.004

Ryan, C. (1993). Crime, violence, terrorism and tourism: An accidental or intrinsic relationship? Tourism Management, 14(3), 173-183. https://doi.org/10.1016/0261-5177(93)90018-G

Schultz, F., Utz, S. y Göritz, A. (2011). Is the medium the message? Perceptions of and reactions to crisis communication via twitter, blogs and 
traditional media. Public Relations Review, 37(1), 20-27. https:// doi.org/10.1016/j.pubrev.2010.12.001

Seltzer, T. y Mitrook, M. A. (2007). The dialogic potential of weblogs in relationship building. Public Relations Review, 33(2), 227-229. https://doi.org/10.1016/j.pubrev.2007.02.011

Shuai, X., Pepe, A. y Bollen, J. (2012). How the scientific community reacts to newly submitted preprints: Article downloads, twitter mentions, and citations. PloSone, 7(11), e47523. https://doi.org/10.1371/ journal.pone.0047523

Sönmez, S. F., Apostolopoulos, Y. y Tarlow, P. (1999). Tourism in crisis: Managing the effects of terrorism. Journal of Travel Research, 38(1), 13-18. https://doi.org/10.1177/004728759903800104

Stephens, K. K. y Malone, P. C. (2009). If the organizations won't give us information: The use of multiple new media for crisis technical translation and dialogue. Journal of Public Relations Research, 21(2), 229-239. https://doi.org/10.1080/10627260802557605

Sweetser, K. D. y Metzgar, E. (2007). Communicating during crisis: Use of blogs as a relationship management tool. Public Relations Review, 33(3), 340-342. https://doi.org/10.1016/j.pubrev.2007.05.016

Ulmer, R. R. y Sellnow, T. L. (2002). Crisis management and the discourse of renewal: Understanding the potential for positive outcomes of crisis. Public Relations Review, 28(4), 361-365. https://doi. org/10.1016/S0363-8111(02)00165-0

Ulmer, R. R., Seeger, M. W. y Sellnow, T. L. (2007). Post-crisis communication and renewal: Expanding the parameters of post-crisis discourse. Public Relations Review, 33(2), 130-134. https://doi. org/10.1016/j.pubrev.2006.11.015 
Uşaklı, A., Koç, B. y Sönmez, S. (2017). How 'social' are destinations? Examining European DMO social media usage. Journal of Destination Marketing y Management, 16(2), 136-149. https://doi. org/10.1016/j.jdmm.2017.02.001

Van der Meer, T. G. y Verhoeven, P. (2013). Public framing organizational crisis situations: Social media versus news media. Public Relations Review, 39(3), 229-231. https://doi.org/10.1016/j.pubrev.2012.12.001

Wan, S., Koh, R., Ong, A. y Pang, A. (2015). Parody social media accounts: Influence and impact on organizations during crisis. Public Relations Review, 41(3), 381-385. https://doi.org/10.1016/j.pubrev.2015.01.002

Wang, B. y Zhuang, J. (2017). Crisis information distribution on Twitter: A content analysis of tweets during Hurricane Sandy. Natural Hazards, 89(1), 161-181. https://doi.org/10.1007/s11069-0172960-x

$\mathrm{Xu}, \mathrm{J} . \mathrm{yWu}, \mathrm{Y}$. (2015). Using Twitter in crisis management for organizations bearing different country-of-origin perceptions. Journal of Communication Management, 19(3), 239-253. https://doi.org/10.1108/ JCOM-06-2013-0050

Zhang, G., Yang, Y. y Mao, X. (2011). Disaster recovery evaluation PROC model framework based on information flow. En Computer Science and Network Technology (ICCSNT), 2011 International Conference on (vol.3,pp. 1841-1845). IEEE. 10.1109/ICCSNT.2011.6182328 